\title{
Delayed Citrus Stimulation and Prevention of Salivary Glands Damage in Patients of Thyroid Carcinoma Treated by Radioiodine Therapy

\author{
Sharmin $\underset{1}{\operatorname{Reza}} \mathbf{1}_{\text {National Institute of Nuclear Medicine \& Allied Sciences, }}^{\mathbf{1}}{ }_{2}$ Bangladesh University of Health sciences
}

Correspondence Address: Dr. Sharmin Reza, Assistant Professor, National Institute of Nuclear Medicine \& Allied Sciences, Block-D

7-10th floor, Bangabandu Sheikh Mujib Medical University (BSMMU), Campus, Dhaka-1000, Bangladesh,

email:rezasharmin19@gmail.com

\begin{abstract}
Objective: It is well established that citrus stimulation has a definite role in preventing salivary gland damage after radioiodine therapy. The aim of this study was to observe how effectively this stimulation can be used to prevent salivary gland damage and whether the timing of sucking citrus substances play any role in preventing this damage more effectively.

Patients and Methods: A total of 128 differentiated thyroid cancer (DTC) patients who received radioiodine treatment for thyroid carcinoma were divided into two groups- group-A and group-B. Group-A patients started citrus stimulation 1 hour after radioiodine ingestion and group-B patients started 24 hours after RAIT. Patients were followed-up at 5 th day, 3rd month, and 6th month after RAIT. Follow up procedure consisted of physical examination and history of pain and swelling in salivary gland regions, taste dysfunction and dryness of mouth.

Result: The incidence of different types of salivary glands side effects and abnormal scan findings were significantly high in the group of patients who were advised to start citrus stimulation $1 \mathrm{~h}$ after radioiodine ingestion. On the other hand, patients who started citrus stimulation $24 \mathrm{~h}$ after RAIT suffered less from salivary gland side effects.

Conclusion: This study showed that delayed initiation of citrus stimulation was more effective in reducing salivary gland damage after RAIT.
\end{abstract}

Key words: Radioiodine ablation, Citrus stimulation, Differentiated thyroid cancer.

Bangladesh J. Nucl. Med. Vol. 21 No. 2 July 2018

Doi: https://doi.org/10.3329/binm.v21i2.40358

\section{INTRODUCTION}

DTC is one of the most common malignancy of the endocrine system. Radioiodine therapy (RAIT) is used after thyroidectomy to ablate the residual thyroid remnant and to treat thyroid cancer metastases (1).
The radioactive decay of ${ }_{131} \mathrm{I}$ emits gamma rays and beta particle (2). Generally, gamma rays pass through tissues without interaction or damage to cellular elements but $94 \%$ of radiation from $131 \mathrm{I}$ originates from beta particles (electron) and collide with cellular elements to cause nuclear damage (3)

After oral administration of radioiodine (131I), it gets concentrated in the blood stream and then taken up by the thyroid cells (4). The basolateral membranes of thyrocytes facing toward the capillaries contain a sodium/iodide symporter (NIS) or iodine pump (5). This symporter transports two $\mathrm{Na}+$ and one I-ion into the cell with each cycle, against the electrochemical gradient for I-. Thus NIS enables the production of intracellular iodine which makes the concentration reach about 20-40 times higher than plasma (6). Besides thyroid gland, many other normal tissues in human body including salivary glands, gastric mucosa, placenta, cillary body of eyes, choroid plexus and mammary glands own NIS and transport iodide against a concentration gradient (7)

Accumulation of radioactive iodine in cells other than thyroid follicular cells induces damage to these cells and salivary glands are the main organs that suffer from damage following RAI therapy. The concentration of ${ }_{131} \mathrm{I}$ in the secreted saliva is $20-100$ times more than that of serum $(8,9)$. This critical ability of the salivary glands to concentrate $131 \mathrm{I}$ causes significant radiation damage. 
Three major salivary glands, e.g. parotid, submandibular and sublingual and several other minor salivary glands are lining the oral and nasal mucosa and the upper digestive tract (9). The main function of the salivary glands include (i) lubrication, (ii) enhancement of digestion through enzymatic and mechanical manipulation, (iii) mediation of taste and (iv) mechanical function of tongue in the production of speech (v) immunologic defense (10). Saliva plays a vital role in the maintenance of periodontal health. Daily secretion of saliva normally ranges between 800 to 1500 milliliters $(\mathrm{ml})$; the average volume is $1000 \mathrm{ml}$ per day (11). So a loss or decrease of salivary flow or production can impair the ability to perform these functions which may be associated with increased morbidity.

A number of complications ranging from transient sialadenitis (pain and swelling of salivary gland) to severe form of xerostomia (dry mouth), swallowing difficulty, taste dysfunction seriously impair the quality of life of DTC patients for the life long period (12). Therefore, prevention of salivary gland injury is an important issue in RAIT. Among all salivary glands, parotid glands are the largest salivary glands Majority of the patients suffer from some degree of salivary gland dysfunction after RAIT. The symptoms may develop immediately after RAIT or later and progress in intensity with time (13). As the destruction of salivary glands are caused by radiation and there is pain and swelling in the region of affected glands, it is known as radiation sialadenitis. In conjunction with the radiation sialadenitis, secondary complications reported include xerostomia, taste alterations, infection, and increase incidence of dental caries, facial nerve involvement, stomatitis, candidiasis and neoplasia (8).

Some measures are routinely practiced to prevent and treat these complications. They are (1) the use of salivary stimulants (sialagogues) such as ascorbic acid (vitamin C), lemon candy, sour pickle etc, (2) gland massage, (3) good oral hygiene, (4) adequate hydration, (5) mouth wash gurgling, (6) duct probing, (7) use of cholinergic antibiotics like pilocarpine, (8) prophylactic use of aminothiolamifostine - a cytoprotective agent against radiation (14).

Salivary stimulation by citrus agent is a widely used method. Salivary stimulants are assumed to decrease the transit time of radioiodine through the salivary glands, thereby reduce the amount of radiation exposure (15). So, sialagogues and proper hydration are reasonable treatment aids for prevention of radiation induced sialadenitis (16). Use of ascorbic acid (vitamin $\mathrm{C}$ tablet) are being practiced as a precautionary measure for more than 27 years at NINMAS, but a small number of patients still experience salivary symptoms. Nakada $\mathrm{K}$ et al. showed in their study that an early start of sucking citrus agent may induce a significant increase in salivary gland damage (17). The purpose of this study was to observe whether delayed starting of citrus stimulation following RAIT reduces salivary damage more effectively than starting early.

\section{PATIENTS AND METHODS}

This is a clinical trial (Quasi experimental study). The prospective study was carried out at the National Institute of Nuclear Medicine and Allied Sciences (NINMAS), Bangabandhu Sheikh Mujib Medical University (BSMMU) campus, Dhaka for one year. Study included 128 DTC patients who received radioiodine therapy (RAIT) after near total thyroidectomy. Patients were divided into two groups (group A and group B). Among them, sixtyfour patients were included in Group A (early citrus stimulation group) and they received citrus stimulation within 1 hour after RAIT. Group B (delayed citrus stimulation group) also included sixty-four patients and they received citrus stimulation 24 hours after RAIT.

One vitamin $\mathrm{C}$ tablet (Ascorbic acid) every 3 hourly in the daytime for 7 days (6 tablets/day, 1500mg) was prescribed to the patients as a citrus stimulant for 
sucking. The patients of group A were instructed to start sucking the tablets just 1 hour after ingestion of radioiodine capsule. Whereas, group B patients were advised to start sucking 24 hours after RAIT. Daily tolerable intake level for ascorbic acid is $2000 \mathrm{mg}$ for normal adult person (18). All patients were instructed to drink plenty of water and fluid during the first 10 days after RAIT. The onset of sialadenitis, taste dysfunction or dry mouth after $131 \mathrm{I}$ administration were monitored at 5th post therapy day as well as regular follow-ups by thorough history, patient interview and answering of a formatted interviewing patients, including a questionnaire. Three follow ups were scheduled on 5th post therapy day, 2nd followup after 3rd month and 3rd follow-up after 6th month of RAIT.

The study was approved by the Scientific Review Committee of the institute. The objective and procedure were explained in detail to the patients and their attendants with written informed consents. Collected data were compiled and analyzed using computer based software SPSS (Statistical Package for Social Sciences), windows version 15. P value < 0.05 was taken as significant at $95 \%$ confidence level. For statistical analysis, Chi square test was used for qualitative variables and Student's t-test was used for quantitative variables.

\section{RESULTS}

Table 1: Comparison of the incidence of salivary side effects after radioiodine therapy in 1st followup (5th day)

\begin{tabular}{|c|c|c|c|}
\hline \multirow[b]{2}{*}{ Salivary side effects } & \multicolumn{2}{|c|}{ Groups } & \multirow[b]{2}{*}{ p value* } \\
\hline & $\begin{array}{c}\underset{(n=64)}{\text { Group A }} \\
\end{array}$ & $\begin{array}{c}\text { Group B } \\
(\mathrm{n}=64)\end{array}$ & \\
\hline Sialadenitis & $35(54.7)$ & $22(34.4)$ & 0.021 \\
\hline Taste dysfunction & $24(37.5)$ & $12(18.8)$ & 0.018 \\
\hline
\end{tabular}

*Chi-square test was done to measure the level of significance.

Figure within parentheses indicates percentage.

Table 1 shows the incidence of salivary side effects between group A and group B in 1st follow-up are compared and shown in Table I. In group A, sialadenitis and taste dysfunction occurred in 35 (54.7\%) patients and $24(37.5 \%)$ patients respectively. Whereas, in group B, 22 (34.4\%) patients experience sialadenitis and 12 (18.8\%) patients complained of taste dysfunction. There were statistically significant $(p<0.05)$ difference between two groups during first follow up.

Table 2: Comparison of the incidence of salivary side effects after radioiodine therapy in 2 nd follow-up (at 3rd month)

\begin{tabular}{|l|c|c|c|}
\hline \multirow{2}{*}{ Salivary side effects } & \multicolumn{2}{|c|}{ Groups } & \multirow{2}{*}{} \\
\cline { 2 - 3 } & $\begin{array}{c}\text { Group A } \\
\text { (n=64) }\end{array}$ & $\begin{array}{c}\text { Group B } \\
(\mathbf{n}=\mathbf{6 4})\end{array}$ & \multirow{2}{*}{ p value* } \\
\hline Sialadenitis & $27(42.2)$ & $15(23.4)$ & 0.024 \\
\hline Taste dysfunction & $26(40.6)$ & $11(17.2)$ & 0.003 \\
\hline Dry mouth & $30(46.9)$ & $19(29.7)$ & 0.045 \\
\hline
\end{tabular}

*Chi-square test was done to measure the level of significance.

Figure within parentheses indicates percentage.

Table 2 shows comparison of the incidence of salivary side effects at $3 \mathrm{rd}$ month after radioiodine therapy in group A and group B. There were statistically significant $(p<0.05)$ difference in the incidence of salivary side effects between group A and group B at 3rd month after RAIT.

Table 3 shows comparison of the incidence of salivary side effects at 6 months after radioiodine therapy. The incidence of salivary side effects was significantly $(p<0.05)$ higher in group $A$ than in group B.

\begin{tabular}{|c|c|c|c|}
\hline \multirow[b]{2}{*}{ Salivary side effects } & \multicolumn{2}{|c|}{ Groups } & \multirow[b]{2}{*}{ p value } \\
\hline & $\begin{array}{c}\text { Group A } \\
(n=64)\end{array}$ & $\begin{array}{c}\text { Group B } \\
(n=64)\end{array}$ & \\
\hline Sialadenitis & $29(45.3)$ & $16(25.0)$ & 0.016 \\
\hline Taste dysfunction & $20(31.3)$ & $10(15.6)$ & 0.037 \\
\hline Dry mouth & $28(43.8)$ & $15(23.4)$ & 0.015 \\
\hline Obstructive parotitis & $14(21.9)$ & $5(7.8)$ & 0.025 \\
\hline
\end{tabular}

*Chi-square test was done to measure the level of significance. Figure within parentheses indicates percentage.

\section{DISCUSSION}

In this study 128 patients who received radioiodine ablation for thyroid carcinoma were divided into two 
groups (group A and group B) with 64 patients in each group. Age range of the study subjects was between 21 yrs to 65 yrs. In the first follow up at 5 th post therapy day $35(54.7 \%)$ patients of group A complained of pain and swelling in parotid region in comparison to $22(34.4 \%)$ patients of group B (p = $0.021)$. Taste dysfunction occurred in $24(37.5 \%)$ patients of group A and 12 (18.8\%) patients of group B $(p=0.018)$. So, both the features of sialadenitis and taste dysfunctions were more in group A showing a statistically significant $(p<0.05)$ difference. Similar findings were observed by Nakada et al. where the incidence of sialadenitis and taste dysfunction was $40.9 \%$ and $16.1 \%$ in early citrus stimulation group and $27.2 \%$ and $16.0 \%$ in the delayed citrus stimulation group respectively (19).

The 2nd follow-up at 3rd month after RAIT showed that the incidence of sialadenitis in group $\mathrm{A}$ and group B was 27 (42.2\%) and 15 (23.4\%) respectively $(\mathrm{p}=0.024)$. Taste dysfunction occurred in 26 $(40.6 \%)$ and $11(17.2 \%)$ patients respectively in group $A$ and in group $B(p=0.003)$. Dry mouth occurred in $30(46.9 \%)$ and $19(29.7 \%)$ patients of group A and group B respectively $(\mathrm{p}=0.045)$. In this follow-up period the salivary gland side effects were more in group A than in group B.

3rd follow-up was done at 6th month after RAIT. During this time sialadenitis occurred in 29 (45.3\%) patients of group A and 16 (25.0\%) patients of group B $(p=0.016)$. Taste dysfunction occurred in $20(31.3 \%)$ patients of group A and 10 (15.6\%) patients of group B $(p=0.037)$. Dry mouth occurred in $28(43.8 \%)$ patients of group A and 15 (23.4\%) patients of group B ( $p=$ $0.015)$. In this follow-up period, salivary side effects were more pronounced in group-A than in group-B. Few patients complained of salty secretion while mastication which indicates obstructive parotitis. This is due to narrowing of the duct and retention of saliva within the gland. Mandel L mentioned radiation induced inflammation of the ductal epithelium of salivary gland followed by shedding of inflammatory debris within the duct lumen as a possible explanation (19). Constriction of ducts causes accentuation of the symptoms while chewing and salty saliva secretion increases within the mouth cavity. In this study, obstructive parotitis was observed in 14 ((21.9\%) patients of group A and $5(7.8 \%)$ patients of group B $(\mathrm{p}=0.025)$.

Substantially lower ${ }_{131} \mathrm{I}$ uptake is noticed in the remnant thyroid or metastatic thyroid tissue than the normal thyroid gland and clearance of ${ }_{131} \mathrm{I}$ from the systemic circulation may be delayed due to a decreased glomerular filtration rate in the hypothyroid condition (17). So, serum concentration of ${ }_{131} \mathrm{I}$ at an early period (within $1 \mathrm{~h}$ ) after RAIT should be considerably high and continuous sucking of citrus stimulus at that time constantly enhances blood flow to the salivary glands which eventually causes greater exposure of the glands to 131 I. On the other hand, iodine-avid tissues reach a plateau after 24 hours and the majority of radioactivity gets excreted through kidney, causing less 131 I uptake in the salivary glands when there is delayed sucking of citrus agent. So, this study demonstrates that citrus stimulus should be given $24 \mathrm{~h}$ after RAIT to effectively reduce salivary gland damage.

\section{CONCLUSION}

While treating a primary disease, it is not desirable to induce a secondary disease process. Salivary gland damage is a common side effect of RAIT. Many precautionary methods are taken to overcome this problem and citrus stimulation is a widely used method to prevent the unwanted damage. This study showed that the time to start citrus stimulation is very important and also showed that salivary side effects were significantly less with delayed starting of citrus stimulation in DTC patients.

\section{REFERENCES}

1. Kloos RT. Protecting thyroid cancer patients from untoward effects of radioactive iodine treatment. Thyroid 2009; 10(9):925-928. (DOI:10.1089/thy.2009.0236.) 
2. Sorenson JA, Cherry SR, Phelps ME. Physics in Nuclear Medicine. 3rd edition. Philadelphia: Elsevier Science USA 2003.

3. S L Lee. Complication of Radioactive Iodine Treatment of thyroid Carcinoma, Journal of the National Comprehensive Cancer Network 2010;8:1277-87.

4. Chow SM. Side effects of high- dose radioactive iodine for ablation or treatment of differentiated thyroid carcinoma.Journal of Hong Kong College of Radiologists 2005;8:127-135. ( http://dx.doi.org/10.1155/2014/839597)

5. Jhiang SM. Cho J, Ryu KY, Smanik PA, McGaughy VR, Fischer AH, Mazzaferri EL. An immunohistochemical study of $\mathrm{Na}+/ \mathrm{I}-$ sympoter in human thyroid tissues and salivary gland tissues. Encrinology1998; 39 (10): 4416-4418. (DOI:10.1210/endo.139.10.6329)

6. Barrett E. K.Barman M. S , Boitano S, Brooks L. H. Ganong's Review of Medical Physiology. 23rd edition. New York: McGraw-Hill 2010.

7. Vieja ADL, Dohan O, Levy O, Carrasco N. Molecular analysis of the sodium/ iodide sympoter: impact on thyroid and extrathyroidal pathophysiology. Physical Review 2000; 80(3):1083-1105.

8. Mandel J.S. and Mandel L. (2003) Radioactive iodine and the Salivary Glands. Thyroid 2003;13(3)265-271.( PMID:12729475DOI: 10.1089/105072503321582060)

9. Freinkel N, Ingbar SH. Concentrating gradients for inorganic I-131 and chloride in mixed human saliva. Journal of Clinical Investigation 1953;32: 1077-1084.

10. Batsakis, J.G. Physiology, In: Cummings CW. Schuller DE (eds). Otolaryngology Head and Neck Surgery. 3rd edition. vol. 2. St.Louis (USA): Mosby-Year Book, 1998:1210-1222.
11. Guyton A C, Hall J E. Text Book of Medical Physiology. 11th edition, Philadelphia: Elsevier 2006

12. Sultana S. Salivary Gland Dysfunction following Radioiodine Therapy for Differentiated Thyroid Carcinoma. Bangladesh Journal of Nuclear Medicine 2008; 11(1):42 - 45.

13. Malpani BL, Samuel AM, Ray S. Quantification of salivary gland function in thyroid in cancer patients treated with radioiodine. International of Radiation Oncology Biology Physics 1996; 35(3):535-540.

14. Bohuslavizki KH, Klutmann S, Brenner W, Lassmann S, Feyerabend B, Tinnemeyer S, Clausen M, Henze E. (1998) Radio protection of salivary glands by amifostine in highdose radioiodine therapy, The Journal of Nuclear Medicine 1998;39(7):1237-1242. (PMID: 9669401)

15. Creutzig H. High or low dose radioiodine ablation of thyroid remnants? Eur J Nucl Med. 1987;12(10):500-2. PubMed PMID: 3569338.

16. Newkirk K.A, Ringel M.D, Wartofsfy L, Burman K.D. The role of radioactive iodine in salivary gland dysfunction, Ear,nose and Throat journal 2000;79(6): 460-468.

17. Nakada K, Ishibashi $T$, Takei $T$, Hirata $K$, Shinohara $\mathrm{K}$, Katoh S, Zhao S, Tamaki N, Noguchi Y, Noguchi S. Does lemon candy decrease salivary gland damage after radioiodine therapy for thyroid cancer. The Journal of Nuclear Medicine 2005; 46(2):261-266. (PMID: 15695785)

18. Bendich A. (1997) Vitamin C safety in humans, In: Pakcker L, Fuche J (eds). Vitamin C in Health and Disease. New York: Marcel Dekker 1997: 367-379.

19. Mandel L and Liu F. Salivary gland injury resulting from exposure to radioactive iodine: Case report. Journal of American Dental Association 2007; 138(12):1582 - 1587. PMID: 18056102 